\title{
FAILURE OF LOCAL FLUID LOSS TO ACCOUNT FOR DEATH IN EXPERIMENTAL SHOCK
}

\author{
By CHARLES C. SCOTT \\ (From The Lilly Research Laboratories, Indianapolis 6)
}

(Received for publication July 14, 1945)

Since the initial work of Phemister $(1,2)$ and Blalock (3), a large volume of evidence has accumulated which supports the theory that the initiating or primary factor of secondary shock is local fluid loss. In consequence, this concept today is more widely accepted than any other. There is no denying that this factor is one of great importance and in many cases no other explanation may be necessary to explain death. Certainly, in the original works mentioned above, the local fluid loss was very large and occurred quite rapidly, the lost fluid consisting mainly of whole blood. Death happened early or the experiment was stopped and the animal killed. In many cases of shock, however, the progression of events does not proceed so rapidly. Furthermore, the fluid lost from the circulation may be practically pure plasma. Under these circumstances, it is possible that other factors may be more important in causing death.

An important criticism of previous reports demonstrating the quantity of local fluid loss lies in the fact that recovery of the animal could not take place. The design of the experiments was such that to determine the amount of lost fluid, the animal had to be killed if it did not die. The body was transected in the mid-abdominal region and the right and left lower extremities separated at the mid-line, in order to compare the increase of weight of the traumatized leg over the normal. It was thus impossible by this technique to compare fluid loss of animals in shock which recover spontaneously, and those which die. In the following work, this objection was overcome, local fluid loss being measured while the animals were living.

\section{METHOD}

Shock was produced by application of pneumatic venous tourniquets to both thighs in healthy mongrel dogs anesthetized with "Seconal Sodium" (Sodium Propyl-methylcarbinyl Allyl Barbiturate, Lilly). The method has been described previously $(4,5)$. A few minutes before ap- plying the tourniquets, the volume of both lower extremities was measured by immersion in water in a 20-liter percolator. Connected to the latter through the bottom outlet was a $5 \mathrm{~mm}$. (outside diameter) glass standpipe, near the top of which was an etched line. The dog was suspended by the forelimbs and jaw with a differential pulley and lowered into the percolator until the iliac crests of the innominate bones were directly at water level. Adjustment was then made by adding or removing water plus raising or lowering the dog until the meniscus in the standpipe was exactly at the etched line and the iliac crests at water level. The dog was then hoisted from the water, allowed to drain a few seconds and removed from the pulley. The amount of water necessary to refill the percolator to the same level was then ascertained. With practice, it was possible to obtain successive measurements within $25 \mathrm{ml}$., which is a small error when the total measures 3000 to $5000 \mathrm{ml}$. At least two measurements were made for each leg volume determination.

Immediately following removal of the tourniquets, leg volume was again measured, and in many instances, several more determinations were made until death or recovery resulted. Since only a neck incision to record carotid blood pressure was needed, suture of this made possible complete recovery of the dog, provided fatal shock did not ensue.

Two series of animals were subjected to this procedure. One group was carried to a shock index ${ }^{1}$ of 120 , this stage being 100 per cent fatal when no treatment was given. In the other group, the dogs were allowed to reach an index of only 80 , which is a less severe degree of shock.

About two days before the experiment, blood volume was measured using Evans' blue dye. Determination was made by the method of Phillips (6) using a Coleman photoelectric spectrophotometer. Following this, the dogs were anesthetized with "Seconal Sodium" so that all the hair of the caudal half of the body could be removed with clippers. This was necessary in order to facilitate the leg volume measurements.

\section{RESULTS}

Of 21 dogs allowed to attain a shock index of 80 before removal of tourniquets, 12 ( 57 per cent) died. The others made a complete spontaneous recovery. The average amount of fluid lost into the lower extremities of the 2 groups of animals,

$$
1 \text { Shock index }=\frac{\begin{array}{r}
\text { percentage of BP fall } \times \text { Duration } \\
\text { of tourniquet application }
\end{array}}{\text { BP at time of tourniquet removal }}
$$


however, was practically identical. The results are shown in Tables I and II. Furthermore, statistical analyses revealed no significant differences in changes of blood pressure and hematocrits, shock index, or original blood volume. The two groups were thus closely similar in their reaction to this form of shock, except that half the dogs died. No relation existed between original total blood volume and the amount of fluid lost into the legs. Measurement of blood volume was done because of the possibility that ability to withstand local fluid loss might depend on the total original blood volume possessed by the animal. However, this proved not to be the case.

In Table III are found the results with dogs carried to a deeper degree of shock, namely, an index of 120. That this is more severe shock is proved by the 100 per cent mortality in twelve animals. Comparison of these animals with those of Table I, which all recovered, revealed again no statistically significant difference in local fluid loss, blood volume, or blood pressure and hematocrit changes. The mean shock index of animals in Table III, of course, was significantly greater

TABLE I

Local fluid loss in early shock which was followed by spontaneous recovery of all dogs

\begin{tabular}{|c|c|c|c|c|c|c|c|c|}
\hline \multirow{2}{*}{$\begin{array}{c}\text { Dog } \\
\text { number }\end{array}$} & \multicolumn{2}{|c|}{ Blood pressure } & \multicolumn{2}{|c|}{ Hematocrit } & \multirow{2}{*}{$\begin{array}{l}\text { Duration of } \\
\text { tourniquet }\end{array}$} & \multirow{2}{*}{$\begin{array}{l}\text { Shock } \\
\text { index }\end{array}$} & \multirow{2}{*}{$\begin{array}{c}\text { Total blood } \\
\text { volume }\end{array}$} & \multirow{2}{*}{$\begin{array}{c}\text { Leg volume } \\
\text { increase }\end{array}$} \\
\hline & Start & Endt & Start & Endt & & & & \\
\hline $\begin{array}{l}1 \\
2 \\
3 \\
4 \\
5 \\
6 \\
7 \\
8 \\
9\end{array}$ & $\begin{array}{l}m m . H_{g} \\
135 \\
130 \\
155 \\
135 \\
150 \\
155 \\
145 \\
160 \\
140\end{array}$ & $\begin{array}{c}\text { mm. } \mathrm{Hg} \\
100 \\
69 \\
92 \\
106 \\
101 \\
75 \\
102 \\
105 \\
105\end{array}$ & $\begin{array}{l}41.8 \\
24.1 \\
34.3 \\
38.8 \\
40.8 \\
34.9 \\
38.3 \\
42.0 \\
48.7\end{array}$ & $\begin{array}{l}59.2 \\
33.9 \\
49.7 \\
49.7 \\
49.7 \\
54.4 \\
53.5 \\
60.0 \\
68.0\end{array}$ & $\begin{array}{l}\min . \\
363 \\
160 \\
180 \\
433 \\
244 \\
116 \\
280 \\
155 \\
307\end{array}$ & $\begin{array}{r}94 \\
109 \\
80 \\
87 \\
79 \\
80 \\
81 \\
51 \\
73\end{array}$ & $\begin{array}{c}\text { Percentage of } \\
\text { body weight* } \\
9.99 \\
12.29 \\
8.83 \\
10.69 \\
9.00 \\
9.11 \\
9.25 \\
7.86 \\
8.54\end{array}$ & $\begin{array}{c}\text { Percentage of } \\
\text { body weight } \\
5.48 \\
2.55 \\
2.64 \\
4.72 \\
1.99 \\
3.11 \\
5.38 \\
2.65 \\
4.67\end{array}$ \\
\hline Mean & 145.0 & 95.0 & 38.2 & 53.1 & 248.7 & 81.6 & 9.51 & 3.69 \\
\hline Standard Error & 3.54 & 4.59 & 2.27 & 3.14 & 35.4 & 5.21 & 0.441 & 0.452 \\
\hline
\end{tabular}

† At time tourniquets were removed from thighs.

* Determined 2 or 3 days before the shock experiment.

TABLE II

Local fuid loss in early shock which was fatal to all animals

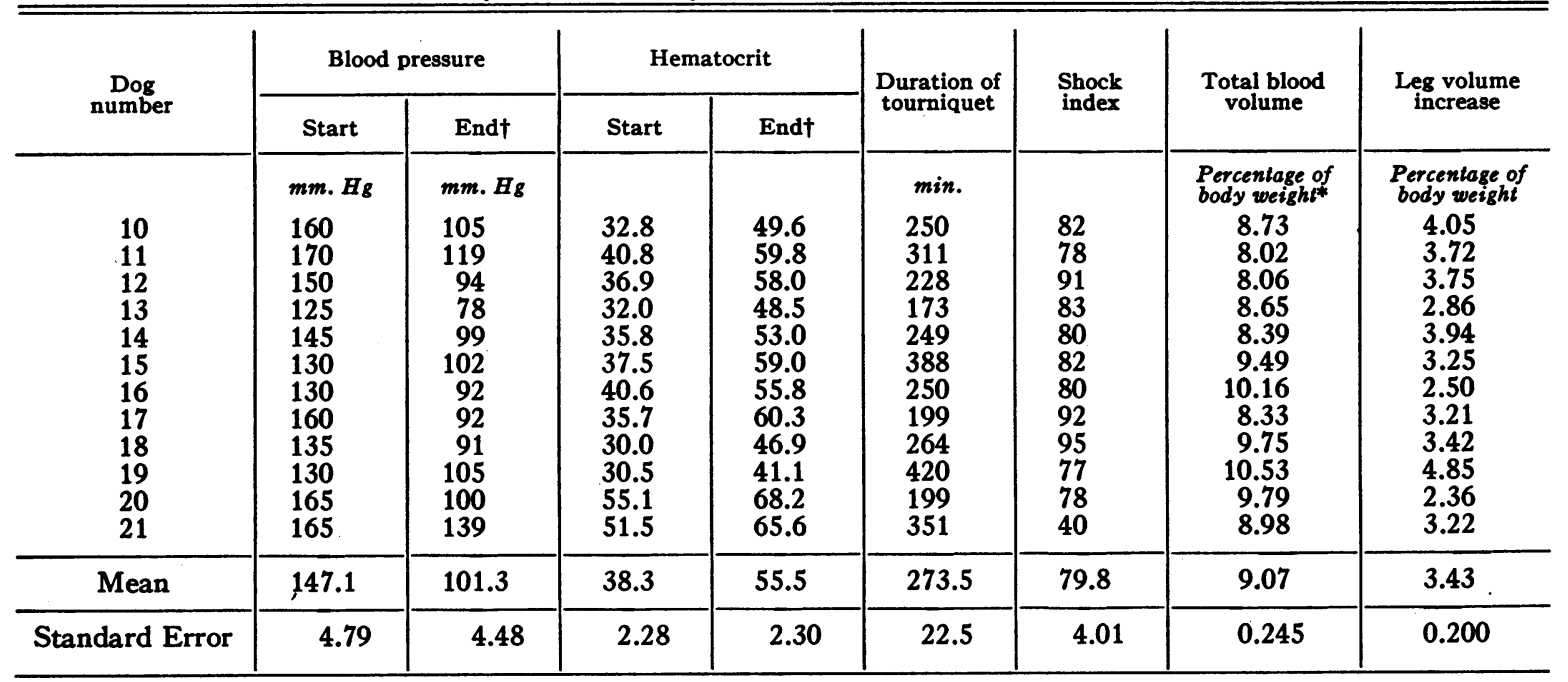

t At time tourniquets were removed from thighs.

* Determined 2 or 3 days before the shock experiment. 
TABLE III

Local fluid loss in deeper shock fatal to all animals

\begin{tabular}{|c|c|c|c|c|c|c|c|c|}
\hline \multirow{2}{*}{$\begin{array}{c}\text { Dog } \\
\text { number }\end{array}$} & \multicolumn{2}{|c|}{ Blood pressure } & \multicolumn{2}{|c|}{ Hematocrit } & \multirow{2}{*}{$\begin{array}{l}\text { Duration of } \\
\text { tourniquet }\end{array}$} & \multirow{2}{*}{$\begin{array}{l}\text { Shock } \\
\text { index }\end{array}$} & \multirow{2}{*}{$\begin{array}{l}\text { Total blood } \\
\text { volume }\end{array}$} & \multirow{2}{*}{$\begin{array}{l}\text { Leg volume } \\
\text { increase }\end{array}$} \\
\hline & Start & Endt & Start & Endt & & & & \\
\hline $\begin{array}{l}22 \\
23 \\
24 \\
25 \\
26 \\
27 \\
28 \\
29 \\
30 \\
31 \\
32 \\
33\end{array}$ & $\begin{array}{l}m m . H g \\
135 \\
160 \\
145 \\
165 \\
160 \\
150 \\
130 \\
150 \\
120 \\
155 \\
140 \\
165\end{array}$ & $\begin{array}{c}m m . ~ \\
\\
9 g \\
96 \\
106 \\
95 \\
108 \\
100 \\
102 \\
85 \\
96 \\
91 \\
106 \\
84 \\
94\end{array}$ & $\begin{array}{l}36.0 \\
41.2 \\
39.4 \\
35.9 \\
38.7 \\
41.5 \\
50.8 \\
40.8 \\
45.5 \\
43.3 \\
43.1 \\
44.6\end{array}$ & $\begin{array}{l}52.4 \\
56.4 \\
62.2 \\
43.4 \\
55.0 \\
62.6 \\
63.1 \\
61.0 \\
65.8 \\
60.0 \\
51.4 \\
53.1\end{array}$ & $\begin{array}{l}\min . \\
400 \\
365 \\
330 \\
371 \\
325 \\
398 \\
299 \\
323 \\
452 \\
410 \\
285 \\
300\end{array}$ & $\begin{array}{l}120 \\
116 \\
120 \\
119 \\
122 \\
125 \\
122 \\
121 \\
120 \\
122 \\
136 \\
137\end{array}$ & 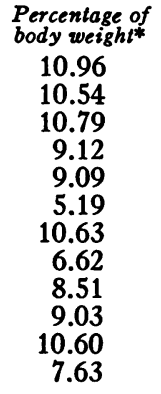 & $\begin{array}{c}\text { Percentage of } \\
\text { body weight } \\
3.95 \\
3.50 \\
3.41 \\
3.68 \\
5.52 \\
4.36 \\
2.68 \\
4.38 \\
4.30 \\
4.65 \\
2.90 \\
5.03\end{array}$ \\
\hline Mean & 147.9 & 96.9 & 41.7 & 57.2 & 354.8 & 123.3 & 9.06 & 4.03 \\
\hline Standard Error & 4.15 & 2.27 & 1.21 & 1.86 & 15.1 & 1.88 & 0.529 & 0.243 \\
\hline
\end{tabular}

$\dagger$ At time tourniquets were removed from thighs.

as was also the duration of tourniquet application. These results indicate that local fluid loss increased only slowly when the shock index passed 80 , yet the mortality rate changed markedly.

The above data are based on leg volume determinations made just before application of tourniquets and immediately following their removal. It is natural to inquire about subsequent local fluid loss, since this might progress for some time and spell the difference between death or spontaneous recovery. With the usual (arterial) type
* Determined 2 or 3 days before the shock experiment.

of tourniquet, it is well known that all the swelling occurs after they are released. Figure 1 shows graphically the variations in leg volume after the tourniquets had been removed. Actually, the changes were very slight and probably insignificant, but are magnified by the graph in order to try to demonstrate any trends. It is readily apparent, however, that no difference could be demonstrated between dogs dying or recovering. Increased fluid loss did occur in surviving animals, while resorption was evident in dogs which failed to re-

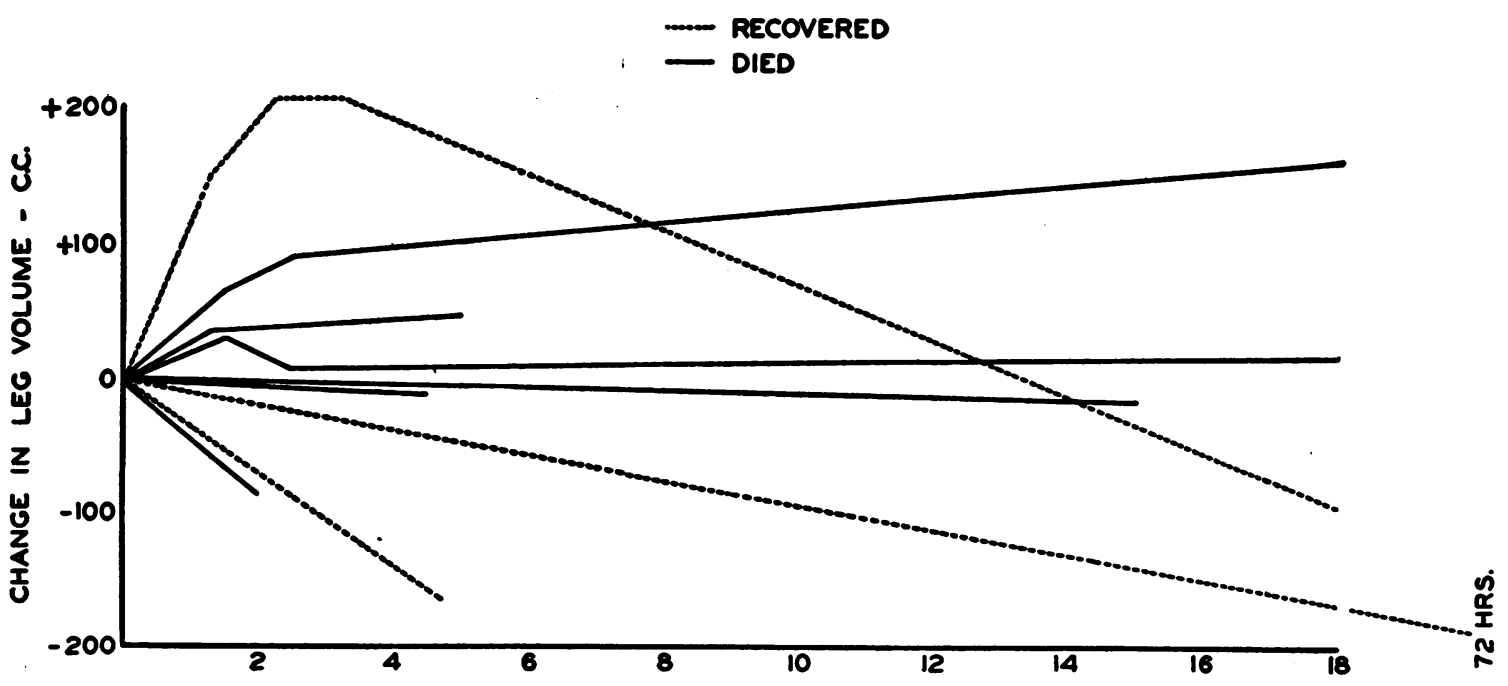

Fig. 1. Changes in Leg Volume Following Removal of Venous Tourniguets in Shocked Dogs

The volume of the swollen leg when the tourniquets were released was taken as the zero. 
cover. The graph is somewhat misleading past the five-hour point in that the exact time of death was not noted in dogs which died at a later hour. Also, animals which recovered were bound to show resorption of the edema fluid.

\section{DISCUSSION}

These results show clearly that when trauma to the extremities is not excessive, local fluid loss fails to account for death of the animal. Some other cause must be the so-called primary factor. Recently, other investigators have inclined to this view. Green and associates (7) noted that the volume of edema fluid in ischemic-compression shock often appeared insufficient to explain death. Estimation of the swelling of crushed legs by measuring their circumference did not allow prediction of survival or death, in experiments by Ricca and associates (8). In an earlier report (4), the author had noted no absolute relation between swelling of the legs and production of shock. On the contrary, there has been increasing evidence that toxic substances are implicated in certain forms of shock, particularly the tourniquet types. Convincing reports have been presented by Aub and co-workers (9) and Prinzmetal and his associates (10). The toxic substance in these studies appeared to be bacterial in origin and death occurred only after many hours. Death from experimental shock by most methods occurs much sooner. Friedberg and Katz (11) suggested that a humoral "toxic" substance played a role, since they could not save any of their dogs with bilateral venous occlusion of the hind limbs, even though plaster casts were applied. Evidence that tourniquet shock in mice results from imbalance between sodium and potassium cations has been offered by Tabor and Rosenthal $(12,13)$. The remarkably effective results obtained by Schachter (14) with cholinesterase alone in treating shock would argue against local fluid loss as the primary factor. Unfortunately, the latter worker did not run recovery experiments, the dogs being killed in about six hours. These results strongly support the view that fatal shock may be caused by factors other than local fluid loss. They do not eliminate the fact that loss of fluid may at times be so large that no other cause need operate to produce a fatal result.
In a previous report (4), it appeared that fatal shock did not occur when the shock index was around 100 or less. A 50 per cent mortality resulted in the present series with a mean shock index of 80 . No sure explanation can be given for this variation, but it should be pointed out that, in the original work, the dogs were not anesthetized two days before the shock experiment. Also they were not subjected to leg volume measurements with suspension in a water-bath. This latter procedure is a strain on the circulatory system even for the normal animal. In some cases, the dogs died during the leg measurements. These additional stresses probably account, in part at least, for the change in the critical shock index level.

\section{SUM MARY}

A method was developed by which it was possible to measure repeatedly leg volume, and thus amount of swelling, in tourniquet shock during life. Consequently, recovery experiments were possible so that comparisons could be made of local fluid loss in fatal and non-fatal shock. By this procedure, there was no difference in the amount of fluid lost into the lower extremities of animals which died and those which spontaneously recovered. Some other factor than local fluid loss must be the primary cause of this type of shock.

\section{BIBLIOGRAPHY}

1. Phemister, D. B., The vascular properties of traumatized and laked bloods and of blood from traumatized limbs. Ann. Surg., 1928, 87, 806.

2. Parsons, E., and Phemister, D. B., Haemorrhage and "shock" in traumatized limbs. Surg., Gynec. and Obst., 1930, 51, 196.

3. Blalock, A., Experimental shock: the cause of the low blood pressure produced by muscle injury. Arch. Surg., 1930, 20, 959.

4. Scott, C. C., and Robbins, E. B., Production of experimental shock in dogs by the use of venous tourniquets. J. Indiana M. A., 1943, 36, 194.

5. Scott, C. C., Worth, H. M., and Robbins, E. B., Comparative value of some blood substitutes used for treatment of experimental shock. Arch. Surg., 1944, 48, 315.

6. Phillips, R. A., A method for the determination of the blue dye T-1824 in plasma. J. Exper. Med., 1943, 77, 421.

7. Green, H. D., Dworkin, R. M., Antos, R. J., and Bergeron, G. A., Ischemic compression shock, with an analysis of local fluid loss. Am. J. Physiol., 1944, 142, 494. 
8. Ricca, R. A., Fink, K., Steadman, L. T., and Warren, S. L., The distribution of body fluids of dogs in traumatic shock. J. Clin. Invest., 1945, 24, 140.

9. Aub, J. C., Brues, A. M., Dubos, R., Kety, S. S., Nathanson, I. T., Pope, A., and Zamecnik, P. C., Bacteria and the "toxic factor" in shock. War Med., 1944, 5, 71.

10. Prinzmetal, M., Freed, S. C., and Kruger, H. E., Pathogenesis and treatment of shock resulting from crushing of muscle. War Med., 1944, 5, 74.

11. Friedberg, L., and Katz, L. N., Observations on shock following bilateral venous occlusion of the hind-limbs of the dog. Am. J. Physiol., 1945, 143, 589.

12. Tabor, H., and Rosenthal, S. M., Experimental chemotherapy of burns and shock. VIII. I. Effects of potassium administration, of sodium loss, and fluid loss in tourniquet shock. Pub. Health Rep., $1945,60,373$.

13. Tabor, H., and Rosenthal, S. M., Experimental chemotherapy of burns and shock. VIII. II. Electrolyte changes in tourniquet shock. Pub. Health Rep., 1945, 60, 401.

14. Schachter, R. J., The use of cholinesterase in shock. Am. J. Physiol., 1945, 143, 552. 